\title{
Abundance of humpback whales in Oceania using photo-identification and microsatellite genotyping
}

\author{
Rochelle Constantine ${ }^{1, *}$, Jennifer A. Jackson, Debbie Steel, C. Scott Baker, \\ Lyndon Brooks, Daniel Burns, Phillip Clapham, Nan Hauser, Bénédicte Madon, \\ David Mattila, Marc Oremus, Michael Poole, Jooke Robbins, \\ Kirsten Thompson, Claire Garrigue
}

${ }^{1}$ School of Biological Sciences, University of Auckland, Auckland 1142, New Zealand

\begin{abstract}
Estimating the abundance of long-lived, migratory animals is challenging but essential for managing populations. We provide the first abundance estimates of endangered humpback whales Megaptera novaeangliae from their breeding grounds in Oceania, South Pacific. Using fluke photo-identification (1999-2004, $\mathrm{n}=660$ individuals) and microsatellite genotypes (1999-2005, $\mathrm{n}=840$ individuals), we estimated abundance with open capture-recapture statistical models. Total Oceania abundance and trends were estimated from 4 primary and 5 secondary sampling sites across the region. Sex-specific genotype data enabled us to account for the difference in capturability of males and females, by doubling male-specific estimates of abundance derived from genotypes. Abundance estimates were congruent between primary- and secondaryregion data sets, suggesting that the primary regions are representative of all Oceania. The best estimate of total abundance was 4329 whales (3345-5313) in 2005, from a sex-specific POPAN super-population model, which includes resident whales and those migrating through the surveyed areas. A doubled-male POPAN abundance estimate from 2003 ( $\mathrm{n}=2941,95 \%$ CI $=$ 1648-4234) was considered the most plausible for the 4 primary survey areas and was similar to the 2003 doubled-male estimate derived from Pradel capture probabilities $(\mathrm{n}=2952,95 \% \mathrm{CI}=$ 2043-4325). Our results confirm that Oceania is the least abundant humpback whale breeding population in the southern hemisphere. Pradel models showed no significant trend in abundance, which contradicts the recovery seen in most other populations throughout the world. Thus we suggest that the whales in this area warrant continued study and management attention.
\end{abstract}

KEY WORDS: Megaptera novaeangliae - South Pacific · Capture-recapture - Genotyping • Endangered species

Resale or republication not permitted without written consent of the publisher

\section{INTRODUCTION}

Managers depend upon abundance estimates to evaluate the status of populations and the effects of human activities. Although some species congregate in relatively discrete areas (e.g. Rayner et al. 2007, Stevick et al. 2008), challenges arise when estimating abundance for species that undertake extensive seasonal migrations and range over large, poorly defined areas. For long-lived, slow-breeding species with large home ranges, such as baleen whales, there are several challenges to estimating abun- dance, especially when managing recovering populations (Hammond 1990, Stevick et al. 2003).

Humpback whales Megaptera novaeangliae congregate to breed during the winter months in Oceania (South Pacific) waters from western New Caledonia $\left(\sim 160^{\circ} \mathrm{E}\right)$ to the French Polynesian archipelago $\left(\sim 120^{\circ} \mathrm{W}\right)$ (Garrigue et al. 2002, Poole 2002) (Fig. 1). Individuals migrate seasonally from these areas to productive Antarctic feeding grounds; most likely to the International Whaling Commission (IWC) Antarctic management areas known as Areas V $\left(130^{\circ} \mathrm{E}-170^{\circ} \mathrm{W}\right)$ and VI $\left(120-180^{\circ} \mathrm{W}\right)$ (Dawbin 1966). 


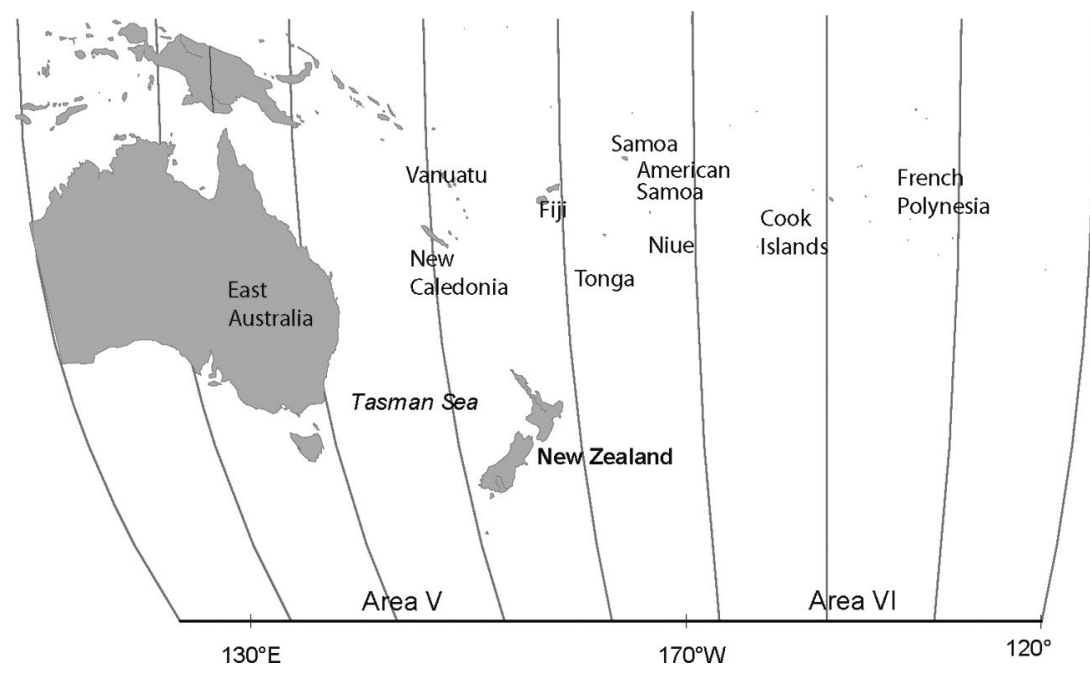

Fig. 1. Oceania, showing the primary and secondary study sites

markers also show connectivity between these sub-populations (Helweg et al. 1998, Garland et al. 2011, Garrigue et al. 2011a). These findings, along with the recent International Union for Conservation of Nature (IUCN) listing, suggest that until further research is conducted, Oceania should be considered as a single population with varying degrees of sub-population structuring throughout the regions (Childerhouse et al. 2008).

The interchange of whales between the Oceania island groups appears to be greater than that observed between Oceania and east Australia (Garrigue et al. 2002,

The specific routes taken are poorly understood, but individuals have been reported in Areas V, VI and I (Steel et al. 2008, Hauser et al. 2010, Robbins et al. 2011). Recent satellite telemetry work has provided some insight into migration paths (Garrigue et al. 2010, Hauser et al. 2010).

In 1999, the South Pacific Whale Research Consortium initiated a coordinated, synoptic survey of 4 primary island regions across Oceania: New Caledonia, Tonga (Vava'u), the Cook Islands and French Polynesia (Moorea and Rurutu). Eight additional sites were also surveyed in some years, including Vanuatu, Samoa, American Samoa, Fiji, Niue and the other Tongan island groups (Ha'apai, Niuatoputapu and Eua) (Fig. 1).

A wide range of research tools have been used in this region, including photographic identification (photo-ID), the collection of skin biopsy (or sloughed skin) samples for genetic analysis, acoustic recordings of song, and satellite telemetry. Analyses to date have yielded information on humpback whale distribution, movements, regional abundance, behaviour, genetic differentiation and diversity (Helweg et al. 1998, Garrigue et al. 2004, 2010, 2011a Olavarría et al. 2007, Hauser et al. 2010, Garland et al. 2011). Movements of whales throughout Oceania vary, with some whales showing high levels of site fidelity to breeding grounds (e.g. New Caledonia; Garrigue et al. 2004), whereas other areas (e.g. Cook Islands) mostly function as a migratory corridor, mainly to Tonga, rather than a breeding ground (Hauser et al. 2010, Garrigue et al. 2011a). There is molecular evidence for limited maternal gene flow, suggesting the existence of sub-populations across Oceania (Olavarría et al. 2007), but photo-ID, song and molecular 2011a,b). A comparison of fluke photo-ID catalogues ( $\mathrm{n}=1242$ from east Australia; $\mathrm{n}=672$ from Oceania and New Zealand) yielded a total of 7 whales from east Australia matched to New Caledonia and New Zealand (a migratory corridor) between 1999 and 2004 (Garrigue et al. 2011b). Similar results were found using molecular markers (Anderson et al. 2010). In contrast, a total of 28 cases of interchange were observed between Oceania island groups during the same period ( $\mathrm{n}=949$ individual whales) (Garrigue et al. 2011a). Although the degree of separation between the east Australia and Oceania populations is still not completely understood (e.g. Valsecchi et al. 2010), the extremely low levels of interchange between Oceania and east Australia and the genetic differences suggest they are not the same population (Anderson et al. 2010), but the level of differentiation found between the 2 populations is likely to be variable, depending on which Oceania region is used for comparison.

The recovery status of humpback whales in Oceania is of great interest, given the well-documented impact of whaling on this breeding ground. The late 19th century saw the beginning of humpback whale hunts in the South Pacific and 20th century whaling was responsible for more than 45000 whales being killed in the Southern Ocean regions associated with Oceania (Areas V and VI) (Clapham \& Ivashchenko 2009). The greatest impact was rendered by illegal Soviet whaling (1947-1973), in particular the 1959-1960 and 1960-1961 summer seasons when 25474 humpbacks were killed in the region south of Oceania; over 20000 of these were from Area V south of east Australia and New Zealand (Clapham et al. 2009). 
Since commercial whaling ceased, evidence for the recovery of South Pacific humpback whales has been variable. Strong increases in abundance have been observed in east Australia (Paterson et al. 2001, Noad et al. 2006a, Paton et al. 2011) whereas the numbers of humpback whales in adjacent Oceania waters appear to remain low, including in areas where numerous whales were previously reported, e.g. Fiji and New Zealand (Dawbin 1959, Gibbs et al. 2006, Constantine et al. 2007). Humpback whales are now found in established breeding grounds in the French Polynesian archipelago, with increased reports of whales off Pitcairn Island; whales in these areas are further east than reported prior to whaling (Poole 2002, 2006, Gibb 2009).

Here we report the first estimates of abundance and trends for the endangered humpback whales that breed in Oceania (IWC breeding stocks E2-F). We use fluke photo-ID and sex-specific microsatellite genotype data collected from 6 yr of synoptic surveys (1999-2005) from 4 breeding areas within the region: French Polynesia, New Caledonia, Tonga and the Cook Islands.

\section{MATERIALS AND METHODS}

\section{Study regions and data collection}

Dedicated surveys for humpback whales were conducted during the austral winters of 1999 to 2005 (referred to as the 'synoptic years'), during which effort was relatively similar in 4 primary study areas: New Caledonia, Tonga, the Cook Islands and French Polynesia (Fig. 1; see Garrigue et al. 2011a for study site details). However, humpback whale breeding habitat in Oceania spans a wide range of islands, reefs and atolls from New Caledonia in the west to French Polynesia in the east, and directed or opportunistic surveys have been conducted at other sites in one or more synoptic years (for more information on study regions, see the Supplement, available at www.int-res.com/articles/suppl/m453p249_supp. pdf). We used available data from American Samoa, Fiji, Niue, Samoa and Vanuatu to investigate the effects of spatial bias and sample size on our estimates.

Data were collected in different ways depending on the field site. In some places, tissue samples were collected primarily from biopsies (e.g. New Caledonia), whereas in other locations we collected sloughed skin (e.g. Cook Islands) or a mixture of both (e.g. Tonga and French Polynesia). These samples were sometimes accompanied by a photo-ID image, but this was not the case for the majority of data points. Overall, there were too few biopsy sample captures accompanied by a fluke image, so models incorporating 2 data sources (e.g. Madon et al. 2011) could not be used to generate a population estimate for the whole Oceania region.

\section{Microsatellite database}

Biopsy and sloughed skin samples were collected from 6 breeding regions in Oceania (New Caledonia, Tonga, Cook Islands, French Polynesia, Samoa and American Samoa) between 1999 and 2005. Total cellular DNA was isolated from skin tissue by digestion with Proteinase $\mathrm{K}$, followed by a standard phenol: chloroform extraction method (Sambrook et al. 1989, Baker et al. 1994). Up to 17 microsatellite loci were amplified for 1447 samples using the following previously published primers: GT211, GT575 and GT23 (Bérubé et al. 2000); GATA417 and GATA28 (Palsbøll et al. 1997); Ev1, Ev14, Ev21, Ev37, Ev94, Ev96 and Ev104 (Valsecchi \& Amos 1996); 464/465 (Schlotteröer et al. 1991); and rw26, rw31, rw4-10 and rw48 (Waldick et al. 1999). Microsatellite loci were amplified individually in a 96- or 384-well format with MJ PTC-225 thermocyclers (MJ Research), and coloaded in 4 sets for automated sizing (size standard 500LIZTM) on an ABI 3730xl (Applied Biosystems) (see Table S1 in the Supplement for thermocycling conditions and co-load groups). Peaks were reviewed and allele bins were allocated using GeneMapper (Applied Biosystems), with all automated calling double-checked by eye (Bonin et al. 2004). Molecular identification of sex and sequencing of the mtDNA control region (470 bp) followed previously used methods (Olavarría et al. 2007).

Genotypic error rates were calculated per allele (Pompanon et al. 2005) using the internal control samples amplified in every PCR. Unique genotypes were resolved with the program CERVUS using criteria that required exact matching for at least 8 loci, supported by control region haplotypes and sex. The average probability of identity for the minimum criterion of 8 matching loci ranged from $1.68 \times 10^{-6}$ to $2.55 \times 10^{-12}$ (depending on the particular combination of 8), calculated following Paetkau et al. (1995). Pairs of genotypes that matched at 8 loci but mismatched at 1-3 loci were reviewed and repeated if necessary to verify the individual's identity or difference.

Data organisation, analyses of microsatellite allele frequency and analysis of probability of identity for 
each microsatellite locus and mtDNA were conducted using GenAlEx (Peakall \& Smouse 2006). GENEPOP v4.0 (Rousset 2008) was used to test for linkage disequilibrium, and CERVUS (Marshall et al. 1998) and DROPOUT (McKelvey \& Schwartz 2005) were used to identify whether any amplified loci were error prone. Based on these analyses, 2 loci (rw4-10 and rw26) were shown to be linked. A search of GenBank showed rw26 to be nested within rw410, and so rw26 was removed from the data set.

Variation in the number of microsatellite loci amplified successfully suggested relatively poor quality DNA for some samples, particularly from sloughed skin. Following a quality control (QC) review, samples with fewer than 10 successfully amplified microsatellite loci were deleted from the data set, leaving a total of 1305 QC samples, each with an average of 15.2 microsatellite loci. Given the large number of loci and the potential for false exclusion because of allelic dropout and other genotype error (Waits \& Leberg 2000, Waits et al. 2001), the initial comparisons allowed for mismatches at up to 3 loci.

\section{Photo-ID database}

Humpback whales were individually identified from photographs of the ventral fluke pattern (Katona et al. 1979) between 1999 and 2004 from the 4 primary and 5 secondary regions. Regional catalogues were compiled and reconciled by the catalogue holders each year for within-region matches. These catalogues were then matched using rational pair-wise comparisons in order to determine between-region re-sightings and a fully reconciled, quality controlled (QC) Oceania catalogue was created (Garrigue et al. 2011a). All images of the QC Oceania catalogue were reviewed according to a set of criteria originally developed for North Pacific humpback whale research (Calambokidis et al. 2001). This system is based on objective quality measures of each image, irrespective of distinctiveness of the fluke. There are 5 quality criteria, each scored on a scale from 1 (highest) to 5 (lowest). These 5 categories were (1) proportion of the fluke visible, (2) vertical angle, (3) the lateral angle, (4) focus and (5) exposure (Calambokidis et al. 2001). An image that received a score of 4 or 5 in any of the 5 quality categories was judged to be of insufficient quality for a standardised comparison of within-region return rates and between-region re-sighting rates. The mark distinctiveness was not assessed, as Oceania humpbacks have predominantly white undersides to their flukes and marks are typically quite distinct; therefore, the photograph QC measures were considered sufficient for this data set. As recommended by Friday et al. (2000), the quality control review of all catalogues was undertaken by a single researcher (R. Constantine) to ensure consistency. Exhaustive matching of all regional catalogues using the $\mathrm{QC}$ scores resulted in a single $\mathrm{QC}$, fully reconciled catalogue for Oceania.

\section{Capture-recapture analysis}

Data sets

Two sets of encounter histories were constructed for each individual in the study. The first was based only on captures in the 4 primary regions (SYN), whereas the second also included captures in the 5 secondary regions (ALL). Each capture occasion consisted of one winter survey season. For the genotype data set these spanned 1999-2005, although no data were available in 2004 from Tonga or the Cook Islands. For the photo-ID data set, encounter histories spanned 1999-2004. There was some overlap of individuals between the 2 data sets because photo-ID data were sometimes obtained in conjunction with biopsy samples. However, the number of whales identified through both genetic and photographic means (double-tagged) was unknown but low across all regions (due to known differences in effort), so each data set was analysed independently.

Because genetic samples were not available for Tonga or the Cook Islands in 2004, we explored the sensitivity of estimates to this uneven sampling by removing all captures from 2004, and specifying the given sampling intervals $(1999-2003,2005)$ in the program MARK (White \& Burnham 1999). Individual region data sets were also constructed for New Caledonia, Tonga and French Polynesia. The Cook Islands were not analysed individually as recaptures were sparse $(\mathrm{n}=2)$.

For the purpose of goodness-of-fit testing, we also created a multi-strata data set, spatially subdividing the SYN data set into 3 general regions: New Caledonia, Tonga/Cook Islands and French Polynesia. Tonga and the Cook Islands were pooled because there are a number of within-season recaptures between these locations, which cannot be accommodated by the current multi-strata models in MARK.

Recapture rates are substantially greater for males than females, which may be an artefact of migratory behaviour, residency on the breeding ground or 
other differential behaviours (Brown et al. 1995, Craig \& Herman 1997, Palsbøll et al. 1997, Smith et al. 1999). This introduces heterogeneity of capture probabilities; therefore, for the genotype data set, data were either analysed as a single group (i.e. both genders pooled) to allow comparison with the photoID data, or stratified by sex.

Tests of goodness-of-fit and closure assumptions

To determine which model types best fit these data sets, we carried out tests of the goodness-of-fit of single-state, multi-strata and regional Oceania data to Cormack-Jolly-Seber (CJS) mark-recapture models using the programs U-CARE (V2.3.2) (Choquet et al. 2005) and MARK (V6.1). Using U-CARE, we tested the goodness-of-fit of the general mark-recapture model over all tests using a CJS framework for the pooled Oceania data sets and for individual regions, and using Jolly-Move and variants for the multistrata data set. Tests 3.SR, 3.Sm, 2.CT and 2.CL (single-state), and WBWA, 3G.SR, 3G.Sm, M.ITEC, M.LTEC (multi-strata) were implemented, along with single- and multi-state tests over all groups. Full descriptions of the tests and summary results are provided in the Supplement and in Table S2.

Model over-dispersion was also examined by calculating the median $\hat{c}$ parameter for the most general, fully identifiable model among all the CJS models of each data set (600 simulations). The parameter $\hat{\mathrm{c}}$ is the deviance of a given model relative to the most parameter-saturated model, divided by the degrees of freedom of the given model. To calculate median $\hat{c}$, data are simulated for a variety of $\hat{c}$ values. The $\hat{\mathrm{C}}$ values are then regressed to find the median $\hat{\mathrm{C}}$ value (i.e. the value at which half the simulated $\hat{c}$ values are higher and half are lower). There is no recommended rationale for how to apply c corrections to open population models, such as POPAN and Pradel. However, we prefer to use CJS ĉ corrections, rather than none at all, as the fit uncertainty identified in the recaptures (CJS) part of the model is likely to indicate fit uncertainty in the whole Jolly-Seber model. The $\hat{c}$ corrections generally favour lowerparameter models in terms of Akaike's information criterion (AIC) and increase standard errors, reflecting reduced confidence. Therefore, where $\hat{c}$ estimates were $>1$, we applied the relevant corrections to our open population models. Results were then compared with those provided by $\hat{c}$ uncorrected models.

Because the data were collected over a 6 to $7 \mathrm{yr}$ period, we assume that the population may have undergone significant input from births and deaths during this time and is not closed. Nevertheless, we also tested for significant violations of population closure assumptions using the program CLOSETEST (Stanley \& Burnham 1999).

Features of the mark-recapture data sets

The results of the goodness-of-fit tests were used to determine the most appropriate population abundance models for these data (Tables S2 \& S3 in the Supplement). TEST 3.SR (transience test) for males (ALL and SYN data sets) was significant across all tests. The significant cohorts were from 2000, 2001 and 2003. TEST 2.CT for females (ALL and SYN data sets) was significantly positive (trap shyness), particularly in the years 2001 and 2002, for the 2-sided test and standardised log odds ratio statistic. Trap shyness of females was not significant for any individual region. The SYN and ALL photo-ID data sets also returned a significant transience signal. Results for ALL and SYN data sets were very similar, so only SYN data sets are shown.

When the data were analysed by the 3 general regions (New Caledonia, Tonga/Cook Islands and French Polynesia; tests weighted equally), TEST 3G.SR (transience test) was significant for New Caledonia (years 2001 and 2003). No other multi-strata tests were significant. Regional analysis of $\mathrm{New}$ Caledonia genotype data alone revealed the same pattern, with years 2000, 2001 and 2003 significant. The 1-sided test for transience $(p=0.049)$ was also marginally significant for females from this region. The 1-sided log odds ratio test for transience was also marginally significant for males in Tonga $(p=0.049)$.

The CJS models explored for the genotype data sets are shown in Table S4 in the Supplement. Median $\hat{c}$ values were estimated from the most parameter-rich fully identifiable model explored for each data set, and were 0.975 (SE =0.03), $1.131(\mathrm{SE}=0.02)$ and 0.981 (SE = 0.02) for SYN, SYN (no 2004) and ALL genotype data sets, respectively. As only the SYN (no 2004) data set yielded a median $\hat{c}>1$ (suggesting slight over-dispersion of data relative to the model), the correction was only applied to this data set. All data sets showed strong support for time-dependent capture probabilities and constant survival rates through time. Genotype models where capture probabilities varied between the 2 sexes were most strongly supported (Table S4 in the Supplement), indicating differential capturability of the 2 sexes. The most strongly supported fully identifiable 
models allowed female capture probabilities to differ from male capture probabilities according to an additive model where male and female capture probabilities differ according to a logit-transformed coefficient. Female capture probabilities were uniformly lower than those of males. The most strongly supported survival models for genotype data allowed the first male cohort survival parameter to vary from all other cohorts (time since marking [TSM] model). However, in these models, the non-first cohort survival rates were often indistinguishable from 1 . This result is consistent with the non-significant result of the CLOSETEST test for population closure; this suggests either that the test had insufficient power to detect population change, or that inputs from births and losses through mortality are not sufficiently large over the $7 \mathrm{yr}$ period to significantly violate assumptions of population closure. Given this uncertainty, although we acknowledge closed models could accommodate variable capture probabilities over time, we decided to focus our exploration on open population models, as capture effort varies between years and the data sets span a time period of several years.

We decided not to use models that explicitly exclude or suppress the transient individuals, as we assume that these transients are more closely associated with the Oceania breeding ground than with any neighbouring breeding area, e.g. east Australia (Garrigue et al. 2011b), and this study aims to estimate overall Oceania abundance.

The photo-ID data sets strongly supported models with time-constant capture probabilities. Median C values were 0.924 (SE 0.03) and 0.794 (SE 0.11) for the SYN and ALL data sets, respectively. This suggests that the data are under-dispersed, so no ĉ correction was employed for these data. A sex-aggregated TSM model was most strongly supported for this data set. Because capture heterogeneity between the 2 sexes is strongly indicated for the genotype data set, the photo-ID data set is likely to include substantial capture heterogeneity.

\section{Choice of models for estimating abundance}

We chose to apply the Pradel model as it permits estimation of population growth $(\lambda)$ as well as survival $(\phi)$, which may have significant population impacts over the $7 \mathrm{yr}$ study period. The Pradel method is based only on events since marking, making no assumptions about events prior to the first capture, as done in Jolly Seber models. To estimate abundance using this approach, it is assumed that marked and unmarked animals (of a given sex) are equally catchable (no capture heterogeneity).

The POPAN model is an extension of the JollySeber model and also assumes equal catchability between marked and unmarked animals on the survey grounds. This formulation additionally assumes that the animals encountered during the survey periods represent a component of a larger super-population (all animals available for capture during the survey), and derives an annual probability of entry of animals from the super-population into the survey regions. The super-population estimate includes the transient component which has been detected in New Caledonia in addition to an overall estimate of Oceania abundance.

\section{Open model abundance estimates}

We estimated the abundance using the POPAN formulation of Schwarz \& Arnason (1996) as implemented in MARK. Because a number of parameters are non-identifiable in POPAN using timedependent capture and survival probabilities, we only explored POPAN models with constant survival probabilities, and with 2 annual capture probabilities (p1 and p7) constrained to be equal where captures were non-identifiable. Best-fitting models were used to derive model-averaged estimates of super-population abundance, and annual abundance using the Delta method to calculate variance. This method determines the variance of random variables with poorly defined distributions by using linear back-transformation.

The Pradel open population model structure (Pradel 1996) was applied to both data sets, co-estimating population growth $(\lambda)$, capture probabilities $\left(p_{t}\right)$ and survival $(\phi)$. Capture probabilities were allowed to vary over time, but $\lambda$ and $\phi$ were modeled as single time-variant parameters. Abundance estimates and their confidence intervals were derived from the capture probabilities of the best-fitting model under AIC criteria, by dividing the numbers of captures in each season by their associated probabilities.

\section{RESULTS}

\section{Genotype data set}

Among all samples available from 1999 to 2005, 1305 of the initial 1447 samples (90\%) passed the QC 
criteria of successful amplification at $>10$ microsatellite loci. Per-allele error rates of $0.58 \%$ and per-locus error rates of $1.11 \%$ were calculated from the QC data set; these errors were corrected within the data sets following the initial matching with fewer loci. From the 1305 QC genotypes we identified 840 individuals, 515 males and 325 females, a sex bias of 1.58:1 males to females. Three individuals were of unknown sex and were therefore not included in the final analysis. Across Oceania, within-year (19992005) sample sizes ranged from 50 to 214 for the SYN data set, with a total of 94 individuals captured in multiple years (Table 1). The ALL data set contained within-year sample sizes between 50 and 231, with a total of 117 individuals captured in multiple years (Tables S5 \& S6 in the Supplement).
Table 1. Summary of humpback whales identified by (A) microsatellite genotypes or (B) fluke photographs, shown by year of capture and recapture across the 4 synoptic survey regions (New Caledonia, Tonga, Cook Islands and French Polynesia)

\begin{tabular}{|c|c|c|c|c|c|c|c|}
\hline \multirow[t]{2}{*}{ (A) Genotypes } & \multicolumn{7}{|c|}{ Year } \\
\hline & 1999 & 2000 & 2001 & 2002 & 2003 & 2004 & 2005 \\
\hline \multirow{2}{*}{$\begin{array}{l}\text { Ind. captured } \\
\text { Cumul. ind. captured }\end{array}$} & 50 & 115 & 181 & 130 & 214 & 79 & 154 \\
\hline & 50 & 162 & 332 & 445 & 623 & 689 & 807 \\
\hline \multirow{2}{*}{$\begin{array}{l}\text { Year of } \\
\text { initial capture }\end{array}$} & \multicolumn{7}{|c|}{ Year of recapture } \\
\hline & 1999 & 2000 & 2001 & 2002 & 2003 & 2004 & 2005 \\
\hline 1999 & $\mathrm{X}$ & 3 & 7 & 3 & 6 & 2 & 2 \\
\hline 2000 & & $\mathrm{X}$ & 4 & 5 & 9 & 3 & 6 \\
\hline 2001 & & & $\mathrm{X}$ & 9 & 17 & 4 & 8 \\
\hline 2002 & & & & $\mathrm{X}$ & 4 & 2 & 8 \\
\hline 2003 & & & & & $\mathrm{X}$ & 2 & 8 \\
\hline \multirow{2}{*}{$\begin{array}{l}2004 \\
2005\end{array}$} & & & & & & $\mathrm{X}$ & 4 \\
\hline & & & & & & & $\mathrm{X}$ \\
\hline \multirow{2}{*}{2005} & $\operatorname{Rec}$ & aptures & & & Total & & \\
\hline & & $2 \times$ & $3 \times$ & & ind. & & \\
\hline No. of ind. & & 14 & 4 & & 94 & & \\
\hline
\end{tabular}

\begin{tabular}{|c|c|c|c|c|c|c|}
\hline \multirow[t]{2}{*}{ (B) Fluke photographs } & \multicolumn{6}{|c|}{ Year } \\
\hline & 1999 & 2000 & 2001 & 2002 & 2003 & 2004 \\
\hline \multirow{2}{*}{$\begin{array}{l}\text { Ind. captured } \\
\text { Cumul. ind. captured }\end{array}$} & 108 & 124 & 132 & 114 & 150 & 110 \\
\hline & 108 & 226 & 338 & 434 & 551 & 627 \\
\hline \multirow{2}{*}{$\begin{array}{l}\text { Year of } \\
\text { initial capture }\end{array}$} & \multicolumn{6}{|c|}{ Year of recapture } \\
\hline & 1999 & 2000 & 2001 & 2002 & 2003 & 2004 \\
\hline 1999 & $\mathrm{X}$ & 6 & 13 & 5 & 8 & 6 \\
\hline 2000 & & $\mathrm{X}$ & 7 & 8 & 10 & 10 \\
\hline 2001 & & & $\mathrm{X}$ & 5 & 7 & 8 \\
\hline 2002 & & & & $\mathrm{X}$ & 8 & 2 \\
\hline \multirow{2}{*}{$\begin{array}{l}2003 \\
2004\end{array}$} & & & & & $\mathrm{X}$ & 8 \\
\hline & & & & & & $\mathrm{X}$ \\
\hline & Recapt & ares & & Tot & & \\
\hline $1 \times$ & $2 \times$ & & $3 \times$ & ind & & \\
\hline No. of ind. & 16 & & 1 & 93 & & \\
\hline
\end{tabular}

\section{Photo-ID data set and recaptures}

A total of 627 individual whales were included in the SYN data set from the synoptic years. Across Oceania, within-year (1999-2004) sample sizes ranged between 108 and 150 photo-IDs for the SYN data set, with a total of 93 individuals captured in multiple years (Table 1). When all regions were considered, a total of 660 individual whales were included in the data set. The ALL data set contained within-year sample sizes of between 108 and 171 photo-IDs, with a total of 101 individuals captured in multiple years (Table S5 in the Supplement).

Model results were very similar with and without the median c corrections for over-dispersion, i.e. confidence intervals widened by $<300$ and estimates differed by $<100$. Only results with the $\hat{c}$ correction are reported below.

\section{Abundance estimates: POPAN models}

Estimates of super-population $\left(\mathrm{N}_{\text {super }}\right)$ abundance using the AICweighted results (Table $\mathrm{S} 7$ in the Supplement) from the POPAN models are shown in Table 2. This superpopulation value represents the total number of individuals in the wider region (assuming no mortality component) as it includes transients. Total super-population abundance estimates were very similar for the male-specific genotype data sets $\left(\right.$ ALL $N_{\text {super }}=2294, C V=0.11 ; \mathrm{SYN}$ 
$\left.\mathrm{N}_{\text {super }}=2164, \mathrm{CV}=0.12\right)$ and for the 2 pooled-sex genotype data sets (3300-3500; Table 2). Photo-ID estimates were much lower by comparison $\left(A L L N_{\text {super }}=2078, C V=0.13\right.$; SYN $\left.\mathrm{N}_{\text {super }}=2032, \mathrm{CV}=0.11\right)$, although levels of precision were similar. From this total, a proportion is estimated to enter the survey region each year and become available for capture. Annual estimates are derived from these proportions (Fig. 2, Tables S7 \& S8 in the Supplement) and are subject to annual mortality. The initial and final years are not shown because estimates of $\mathrm{N}_{\text {super }}$ from these years are not fully identifiable and are therefore not biologically interpretable.

POPAN estimates of annual abundance account for mortality during the survey period. Annual abundances of males were extremely similar between the ALL, SYN and SYN (no 2004) data sets (Fig. 2, Table S8 in the Supplement). Estimated apparent survival (deaths and permanent emigration, $\phi$ ) in the 2 bestfitting models for the SYN data set was high ( $\phi$ (both sexes $)=0.99, \mathrm{AIC}_{\mathrm{c}}$ weight $=0.44 ; \phi($ males $)=0.96$, $\phi($ females $)=1.00$, QAIC $_{\mathrm{c}}$ weight $\left.=0.22\right)$, although confidence intervals were wide.

\section{Abundance estimates: Pradel model}

Best-fitting estimates of population growth $(\lambda)$ and apparent survival $(\phi)$ in the Pradel model were within biologically plausible ranges for all data sets analysed (Table 3, Table S9 in the Supplement). For the genotype data sets, the best-fitting model in each case was $\phi(.) p_{t} \lambda($.), where only capture probability varied over time (Table S10 in the Supplement). The SYN and ALL genotype data sets yielded very similar estimates, with $\lambda=1.03-1.04$ and $\phi=0.94-0.95$. The SYN and ALL photo-ID data sets yielded estimates of $\lambda$ from 1.06 to 1.07 and estimates of $\phi$ from 0.96 to 0.97 (Table 3, Table S10 in the Supplement). No values for survival or population growth were significantly better fitting to any data set than $\phi=1$ and $\lambda=$ 1 , respectively, i.e. there was no significant trend in abundance. As the sex ratio of these data sets is skewed towards males, we also analysed the sexspecific SYN data set to derive male-specific abun- dance estimates (Table 3). Precision (CV) of annual $\mathrm{p}$-values ranged from 0.18 to 0.31 , with the lowest precision in the initial and final years with estimates.

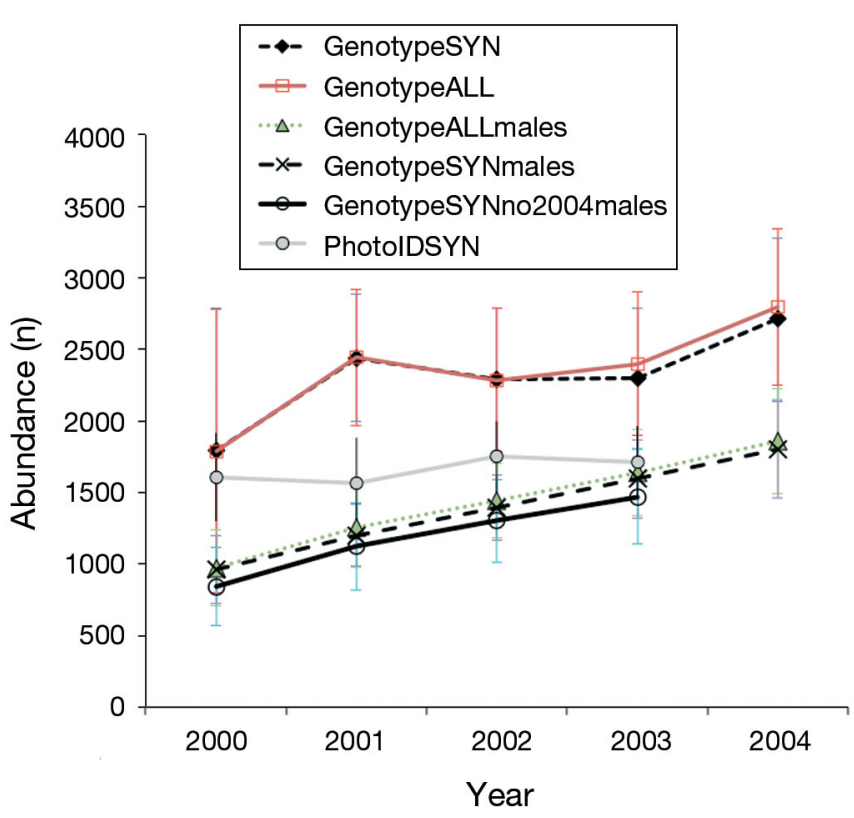

Fig. 2. Annual estimates of humpback whale abundance, with associated standard errors shown as vertical bars. These are derived from AIC-preferred models for the genotype and photo-ID data sets using the Delta method in the POPAN open population model 
Table 3. Estimates of apparent survival $(\phi)$ and apparent population growth $(\lambda)$ estimated for pooled SYN Oceania genotype and photo-ID data sets from the best-fitting mark-recapture models. Capture probabilities over time $\left(p_{t}\right)$ for each data set were estimated from the best fitting $\mathrm{AIC}_{\mathrm{c}}$-weighted Pradel model in MARK. Standard errors are given in parentheses. Abundance was derived by dividing capture probabilities by the number of animals captured in each year $\left(\mathrm{p}_{\mathrm{t}} / \mathrm{n}\right)$. Confidence intervals were derived from the $95 \%$ confidence intervals of each capture probability. For SYN data sets, only male captures were used in order to derive male-specific abundance estimates

\begin{tabular}{|c|c|c|c|c|c|c|}
\hline & \multicolumn{2}{|c|}{ Genotype males } & \multicolumn{2}{|c|}{ Genotype no 2004 males } & \multicolumn{2}{|c|}{ Photo-ID } \\
\hline$\phi$ & \multicolumn{2}{|c|}{0.95} & \multicolumn{2}{|c|}{0.89} & \multicolumn{2}{|c|}{0.96} \\
\hline $\mathrm{SE}(\mathrm{CI})$ & \multicolumn{2}{|c|}{$0.07(0.53-1.00)$} & \multicolumn{2}{|c|}{$0.09(0.60-0.98)$} & \multicolumn{2}{|c|}{$0.07(0.43-1.00)$} \\
\hline$\lambda$ & \multicolumn{2}{|c|}{1.03} & \multicolumn{2}{|c|}{0.98} & \multicolumn{2}{|c|}{0.98} \\
\hline $\mathrm{SE}(\mathrm{CI})$ & \multicolumn{2}{|c|}{$0.07(0.90-1.18)$} & \multicolumn{2}{|c|}{$0.08(0.01-1.00)$} & \multicolumn{2}{|c|}{$0.08(0.8-1.14)$} \\
\hline Year & $\mathrm{p}_{\mathrm{t}}$ & $\mathrm{N}_{\mathrm{t}}(\mathrm{CI})$ & $\mathrm{p}_{\mathrm{t}}$ & $\mathrm{N}_{\mathrm{t}}(\mathrm{CI})$ & $\mathrm{p}_{\mathrm{t}}$ & $\mathrm{N}_{\mathrm{t}}(\mathrm{CI})$ \\
\hline 1999 & $0.023(0.007)$ & $1082(593-1995)$ & $0.023(0.008)$ & $1100(579-2109)$ & $0.059(0.017)$ & $1824(1053-3223)$ \\
\hline 2000 & $0.052(0.013)$ & $1398(874-2263)$ & $0.053(0.014)$ & $1352(824-2252)$ & $0.069(0.016)$ & 1785 (1140-2839) \\
\hline 2001 & $0.078(0.016)$ & $1505(1024-2241)$ & $0.084(0.018)$ & $1386(915-2135)$ & $0.076(0.015)$ & $1747(1190-2597)$ \\
\hline 2002 & $0.055(0.010)$ & $1534(1062-2234)$ & $0.062(0.014)$ & 1345 (881-2080) & $0.067(0.013)$ & $1710(1170-2527)$ \\
\hline 2003 & $0.087(0.017)$ & $1476(1021-2163)$ & $0.105(0.025)$ & 1232 (779-1999) & $0.090(0.019)$ & $1674(1108-2574)$ \\
\hline 2004 & $0.031(0.008)$ & $1311(820-2110)$ & & & $0.067(0.018)$ & $1639(984-2784)$ \\
\hline 2005 & $0.059(0.016)$ & $1498(883-2586)$ & $0.078(0.028)$ & $1133(573-2340)$ & & \\
\hline
\end{tabular}

Abundance estimates derived from the Pradel models (male SYN genotypes $\mathrm{N}=1000-1600$, photo-ID $\mathrm{N}=1630-1830$; Table 3) were the smallest among all estimates derived from these data.

\section{DISCUSSION}

This paper presents the first comprehensive abundance estimates using photo-ID and genotype data for the endangered humpback whales of Oceania. We recommend that the doubled POPAN malespecific super population estimate, $\mathrm{N}=4329(\mathrm{CV}=$ $0.12,3345-5313)$, from the synoptic years is the best estimate for these data. This estimate effectively encompasses animals that remain in the survey areas for some time and transient animals that migrate past to un-surveyed regions without staying. It is also likely to be slightly positively biased because survival rates are not incorporated. However, estimated survival was consistently high $(>0.95)$ so this bias is not likely to be substantial. High survival rates may reflect the short length of the study relative to the long generation time of humpback whales $(21.5 \mathrm{yr}$; Taylor et al. 2007), which is more than 3 times longer than the period of this survey.

For a more conservative estimate of breeding ground abundance (in which the effective survival rates have excluded transients, so animals in un-surveyed regions are not included), we consider that the doubled 2003 male POPAN estimate of abundance from the SYN (no 2004) data set $(\mathrm{N}=2963$, CI
1158-3999; Fig. 2) represents the most plausible abundance of the primary Oceania survey areas. This value is closely consistent with the abundance estimate from the SYN data set and is not influenced by the low effort in 2004, nor is it influenced by the potential widening of the survey area over time, which could create estimation bias in the ALL data set. It is also closely similar to Pradel abundance estimates in this year (Table 3). In the Pradel model, transients are not likely to be incorporated in the abundance estimate because this model is conditioned on recaptures, which by definition do not include transients. We assume that transients are likely to be members of the Oceania breeding population, possibly from poorly surveyed regions such as the Chesterfield Reef, offshore seamounts (Garrigue et al. 2010) or eastern French Polynesia, or animals that are moving through the surveyed areas, only outside the research periods. We consider that they should be included as part of the population until any data suggest evidence to the contrary. Further research in these other areas will help us understand the status of these transient animals.

The estimate of 4329 humpback whales seems to be the most reasonable estimate of local abundance for the Oceania survey areas. Although multi-strata models that explicitly incorporate transience in an open model framework would be desirable for this population, the current data set is sparse and is unlikely to be improved because of the difficulty of increasing study effort in a consistent way across Oceania. 
Our results support the IUCN Endangered listing for this population (Childerhouse et al. 2008) and should be considered as a benchmark in future humpback whale population assessments of the region. Our results suggest that Oceania is the least populous Southern Hemisphere collection of breeding grounds known to date, despite encompassing an enormous range that covers much of the South Pacific (R. Reeves et al. South Pacific Regional Environment Programme, unpubl. rep.). The population trend estimates we present here using the POPAN and Pradel models are indistinguishable from zero, suggesting that for the synoptic years of 1999-2005, this population, at least for the surveyed areas, is not recovering at the rate of neighbouring populations such as east Australia (Paterson et al. 2001, 2004, Noad et al. 2006a, Paton et al. 2011).

The reasons for the low abundance may lie in the intensive hunting pressure on humpback whales south of New Zealand, especially in later years by Soviet whaling fleets on an already severely depleted stock (Clapham et al. 2009). Whaling in these waters is the most likely explanation for the dramatic decrease in whale sightings in regions such as Fiji and New Zealand, where whales were frequently sighted in the 1950s but which exhibit only a slow recovery rate today (Dawbin 1956, Gibbs \& Childerhouse 2000, Gibbs et al. 2006). Strongly bottlenecked animal populations are at risk of depensation (the Allee effect; Courchamp et al. 1999, Stephens \& Sutherland 1999). This is a phenomenon whereby population growth is negatively impacted at low population densities, as small populations suffer one or a combination of inbreeding depression, demographic stochasticity (fluctuations in sex ratio, inability to find mates) and a reduction in cooperative interactions due to low abundance. Further research on calving rates, mortality and a better understanding of breeding ground links with Antarctic feeding grounds may help understand the reasons behind this slow recovery rate.

\section{Comparison of the ALL and SYN data sets}

In general, the photo-ID and genotype ALL data sets produced slightly larger abundance estimates than the SYN data sets, but the magnitude of the difference was not large or significant (Table 2). This suggests that most whales were captured within the synoptic regions, as increasing regional coverage has not led to a significant increase in abundance. It must be noted that effort in these secondary areas was low, with the exception of American Samoa. With this in mind, it is unlikely that increasing the number or range of survey areas will result in a significant difference to future estimates. If other primary areas were included in future surveys, for example American Samoa, the research effort would need to be proportional to abundance, ensuring equal capture probability and thereby avoiding negative bias by minimising heterogeneity of capture probability. In the long term it would also be desirable to explore models that use the photo-ID and genotype data sets as a combined source (i.e. 2-sample models) to generate combined estimates of abundance. It is not possible to do this with the current data sets, as models currently developed for such an approach (Madon et al. 2011) require that the proportion of animals double tagged on each occasion (i.e. animals captured by both genetic biopsy and photo-ID) is $>0.2$. In regions such as the Cook Islands where genetic data has been collected from sloughed skin, photo-ID of the sloughing animal cannot be performed with confidence, so no animals are double tagged. In other regions, e.g. Tonga and French Polynesia, no genetic data were collected in some years. Future estimates of the Oceania humpbacks will ensure sample collection that allows the most robust analysis.

\section{Limitations}

We used open mark-recapture models as they were the best fit to our data sets, whilst recognising that assumptions in these models regarding equal effort across the region are violated. The pooled Oceania abundance estimates are based on low capture probabilities (<0.1), which are associated with model instability and substantial variance in abundance estimates within each model framework. As the survey region is large and data collection resources limited, it is unlikely that these recapture values will be increased. Oceania is known to have significant maternal population structuring across breeding regions (Olavarría et al. 2007), yet our analysis is based on data pooled from across these regions. Multiple recaptures between regions indicate that there is population connectivity across Oceania (Garrigue et al. 2011a). If regions are strongly sub-structured, individuals captured in regions of lower effort (e.g. throughout the French Polynesian archipelago) are less likely to be recaptured than those in regions of high effort (e.g. New Caledonia), introducing spatial capture heterogeneity and therefore a negative bias to consequent abundance estimates when data are pooled. Tests for differential capture using the multi- 
strata data set did not find significant heterogeneity between regions, but it must be cautioned that regional data sets are sparse, so the power to detect significant differences is consequently low.

The genotype estimates were consistently larger than the photo-ID estimates, but both found fewer than 5000 individuals in Oceania. These differences are likely driven by a number of factors, including differences in data collection strategies, different levels of effort over regions and between years, and the differential availability of various age and sex classes of whales for the 2 survey methods (Smith et al. 1999). We are also unable to directly account for any sex-specific capture heterogeneity in the photo-ID data, as the sex of most of these whales is unknown. We hope that future simulations to explore the causes of these differences will enable us to better explain this disparity. Photo-ID overall estimates were roughly equivalent to the genotype-based estimates of males only.

Given that the sex ratio of genotype captures is not at parity (1.58:1 males to females), and we have no reason not to expect the sex ratio of the photo-ID data set to be similarly skewed, models which do not take this capture bias into account may underestimate the true abundance of humpback whales utilising the region. This is because available feeding ground data suggest that the humpback populations are at sexual parity (Glockner-Ferrari \& Ferrari 1990, Clapham et al. 1995) but a consistent pattern of genetic capture of more males than females on breeding grounds and migratory routes is emerging (Brown et al. 1995, Craig \& Herman 1997, Smith et al. 1999). This suggests that females may be less available for genotype or photo-ID capture on the breeding grounds possibly because of sex-specific differences in behaviour or residency times (Craig \& Herman 1997). We therefore suggest that abundance estimates based on the male-specific genotype data, doubled to attain an equal-sexes estimate of total abundance, represents the most appropriate estimate of true humpback whale abundance in the region surveyed (Palsbøll et al. 1997).

\section{Management implications}

Our research supports the recent IUCN Endangered listing (Childerhouse et al. 2008) for the humpback whales from the IWC breeding stocks E2-F. The trend of very low recovery rate for these whales is of concern as it is lower than almost all other known humpback populations. The sanctuaries cre- ated throughout the South Pacific are important in protecting the humpback whales from anthropogenic threats such as habitat degradation (e.g. mining in New Caledonia, fishing gear entanglement throughout their range) and the rapid growth in commercial whale watching (O'Connor et al. 2009, Schaffar et al. 2010). Surveys in remote areas of Oceania such as eastern French Polynesia, the Chesterfield Islands, Pitcairn Island and remote island groups in Fiji and Vanuatu should be conducted to gather a clearer picture of the Oceania population size and range. The interchange rate between humpback whales from east Australia and Oceania is extremely low but we have yet to determine the degree of isolation between these 2 regions (Anderson et al. 2010, Garrigue et al. 2012b). We recommend that another population estimate should be undertaken to provide further trends of recovery. This will allow ongoing assessment of their recovery, which will hopefully be as successful as most other populations throughout the world.

Acknowledgements. This research is a contribution by the South Pacific Whale Research Consortium. We were generously funded by the International Fund for Animal Welfare, French Fonds Pacifique (through Opération Cétacés), the National Marine Mammal Laboratory, the Australian Department of Water, Heritage and Arts RNHP Fund, and the International Whaling Commission Scientific Committee. Thanks to the New Zealand Ministry of Research, Science and Technology funded Broadband enabled Science and Technology GRID (BeSTGRID) for collaborative data storage space. We thank all our collaborators in and out of the field over the years that this research has taken. Research in New Caledonia was made possible by the Provinces Sud, North and Isles, Inco, Fondation d'Entreprise Total and Total Pacifique, and Opération Cétacés was issued a permit by the Province Sud. The Tongan research was conducted under a University of Auckland Animal Ethics permit (C.S.B.) and a research permit issued by the late Tāufa'àhau Tupou IV, King of Tonga. Research in the Cook Islands was permitted by the Government of the Cook Islands. Research in American Samoa was supported by the American Samoa Division of Marine and Wildlife Resources, the Fagatele Bay National Marine Sanctuary and the US National Park of American Samoa. Research activities were conducted under NOAA fisheries permit 774-1437 and a scientific permit issued by the Government of American Samoa. Research in French Polynesia was permitted by the High Commissioner's Office and the Ministry of the Environment and was supported by West Marine Products, Mike Poliza of the Starship Millennium Voyage, the Office des Postes et Telecommunications, Sin Tung Hing Marine and Mercury outboards, Eric Leborgne, Renee Albertson, Hardy Jones-Julia Whitty Productions, Yves Lefevre and the Raie Manta Club, Cine Marine, Marie-Helene Bacconnet, the National Oceanic Society, and Dolphin \& Whale Watching Expeditions. We thank our colleagues, especially those at the IWC Scientific Committee, who made helpful comments on earlier drafts of this manuscript, and the reviewers for their helpful comments. 


\section{LITERATURE CITED}

Anderson M, Steel D, Franklin W, Franklin T and others (2010) Microsatellite genotype matches of eastern Australian humpback whales to Area V feeding and breeding grounds. Paper SC/62/SH7. International Whaling Commission, Cambridge

Baker CS, Slade RW, Bannister JL, Abernethy RB and others (1994) Hierarchical structure of mitochondrial DNA gene flow among humpback whales Megaptera novaeangliae, worldwide. Mol Ecol 3:313-327

Bérubé M, Jorgensen H, McEwing R, Palsbøll PJ (2000) Polymorphic di-nucleotide microsatellite loci isolated from the humpback whale, Megaptera novaeangliae. Mol Ecol 9:2181-2183

Bonin A, Bellemain E, Bronken Eidesen P and others (2004) How to track and assess genotyping errors in population genetics studies. Mol Ecol 13:3261-3273

Brown MR, Corkeron PJ, Hale PT, Schultz KW, Bryden MM (1995) Evidence for a sex-segregated migration in the humpback whale (Megaptera novaeangliae). Proc Biol Sci 259:229-234

- Calambokidis J, Steiger GH, Straley JM, Herman LM and others (2001) Movements and population structure of humpback whales in the North Pacific. Mar Mamm Sci 17:769-794

Childerhouse S, Jackson J, Baker CS, Gales N and others (2008) Megaptera novaeangliae, Oceania subpopulation. IUCN Red List of Threatened Species, Gland. Available at www.iucnredlist.org/details/132832

Choquet R, Lebreton JD, Gimenez O, Reboulet AM, Pradel R (2009) UCARE: Utilities for performing goodness of fit tests and manipulating CApture-REcapture data. Ecography 32:1071-1074

Clapham P, Ivashchenko Y (2009) A whale of a deception. Mar Fish Rev 71:44-52

Clapham PJ, Bérubé M, Mattila DK (1995) Sex ratio of the Gulf of Maine humpback whale population. Mar Mamm Sci 11:227-231

Clapham P, Mikhalev YA, Franklin W, Paton D and others (2009) Catches of humpback whales, Megaptera novaeangliae, by the Soviet Union and other nations in the Southern Ocean, 1947-1973. Mar Fish Rev 71:39-43

Constantine R, Russell K, Gibbs N, Childerhouse S, Baker CS (2007) Photo-identification of humpback whales (Megaptera novaeangliae) in New Zealand waters and their migratory connections to breeding grounds of Oceania. Mar Mamm Sci 23:715-720

Courchamp F, Clutton-Brock T, Grenfell B (1999) Inverse density dependence and the Allee effect. Trends Ecol Evol 14:405-410

Craig AS, Herman LM (1997) Sex differences in the site fidelity and migration of humpback whales (Megaptera novaeangliae) to the Hawaiian Islands. Can J Zool 75: 1923-1933

Dawbin WH (1956) The migrations of humpback whales which pass the New Zealand coast. Trans R Soc NZ 84: 147-196

Dawbin WH (1959) New Zealand and South Pacific Whale marking and recoveries to the end of 1958. Norsk Hvalfangsttid 5:214-238

Dawbin WH (1966) The seasonal migratory cycle of humpback whales. In: Norris KS (ed) Whales, dolphins and porpoises. University of California Press, Berkeley, CA, p 145-170
Friday N, Smith TD, Stevick PT, Allen J (2000) Measurement of photographic quality and individual distinctiveness for the photographic identification of humpback whales, Megaptera novaeangliae. Mar Mamm Sci 16:355-374

- Garland EC, Goldizen AW, Rekdahl ML, Constantine R and others (2011) Dynamic horizontal cultural transmission of humpback whale song at the ocean basin scale. Curr Biol 21:687-691

Garrigue C, Aguayo A, Amante-Helweg VLU, Baker CS and others (2002) Movements of humpback whales in Oceania, South Pacific. J Cetacean Res Manag 4:255-260

Garrigue C, Dodemont R, Steel D, Baker CS (2004) Organismal and 'gametic' capture-recapture using microsatellite genotyping confirm low abundance and reproductive autonomy of humpback whales on the wintering grounds of New Caledonia. Mar Ecol Prog Ser 274:251-262

Garrigue C, Zerbini AN, Geyer Y, Heide-Jørgensen MP and others (2010) Movements of satellite-monitored humpback whales from New Caledonia. J Mammal 91: 109-115

Garrigue C, Constantine R, Poole M, Hauser N and others (2011a) Movement of individual humpback whales between wintering grounds of Oceania (South Pacific), 1999 to 2004. J Cetacean Res Manag Spec Issue 3:275-282

Garrigue C, Franklin T, Constantine R, Russell K and others (2011b) First assessment of interchange of humpback whales between Oceania and the east coast of Australia. J Cetacean Res Manag Spec Issue 3:269-274

Gibb R (2009) Humpback whales (Megaptera novaeangliae) in the South Pacific breeding grounds: an allocation from feeding areas and an abundance estimate of whales specific to French Polynesia waters. MSc thesis, Oregon State University, Corvallis, OR

Gibbs N, Childerhouse S (2000) Humpback whales around New Zealand. Conservation Advisory Science Notes No. 287. Department of Conservation, Wellington

Gibbs N, Paton DA, Childerhouse S, Clapham PJ (2006) Assessment of the current abundance of humpback whales in the Lomaiviti Island Group of Fiji and a comparison with historical data. Paper SC/A06/HW34. International Whaling Commission, Cambridge

Glockner-Ferrari DA, Ferrari MJ (1990) Reproduction in the humpback whale (Megaptera novaeangliae) in Hawaiian waters, 1975-1988: the life history, reproductive rates and behavior of known individuals indentified through surface and underwater photography. Rep Int Whal Comm Spec Issue 12:161-169

> Hammond PS (1990) Capturing whales on film - estimating cetacean population parameters from individual recognition data. Mammal Rev 20:17-22

Hauser N, Zerbini AN, Geyer Y, Heide-Jørgensen MP, Clapham P (2010) Movements of satellite-monitored humpback whales, Megaptera novaeangliae, from the Cook Islands. Mar Mamm Sci 26:679-685

Helweg DA, Cato DH, Jenkins PF, Garrigue C, McCauley RD (1998) Geographic variation in South Pacific humpback whale songs. Behaviour 135:1-27

Katona S, Baxter B, Brazier O, Kraus S and others (1979) Identification of humpback whales by fluke photographs. In: Winn HE, Olla BL (eds) Behavior of marine animals, Vol. 3. Plenum Press, New York, NY, p 33-44

Madon B, Gimenez O, McArdle B, Baker CS, Garrigue C (2011) A new method for estiamting animal abundance with two sources of data in capture-recapture studies. Methods Ecol Evol 2:390-400 
Marshall TC, Slate J, Kruuk LEB, Pemberton JM (1998) Statistical confidence for likelihood-based paternity inference in natural populations. Mol Ecol 7:639-655

McKelvey KS, Schwartz MK (2005) DROPOUT: a program to identify problem loci and samples for noninvasive genetic samples in a capture-mark-recapture framework. Mol Ecol Notes 5:716-718

Noad M, Cato DH, Paton D (2006a) Absolute and relative abundance estimates of Australian east coast humpback whales. Paper SC/A06/HW27. International Whaling Commission, Cambridge

Noad MJ, Paton DA, Gibbs NJ, Childerhouse SJ (2006b) A combined visual and acoustic survey of humpback whales and other cetaceans of Samoa. Paper SC/A06/ HW28. International Whaling Commission, Cambridge

O'Connor S, Campbell R, Cortez H, Knowles T (2009) Whale watching worldwide: tourism numbers, expenditures and expanding economic benefits. Economists At Large, Yarmouth, MA

Olavarría C, Baker CS, Garrigue C, Poole M and others (2007) Population structure of South Pacific humpback whales and the origin of the eastern Polynesian breeding grounds. Mar Ecol Prog Ser 330:257-268

Paetkau D, Calvert W, Stirling I, Strobeck C (1995) Microsatellite analysis of population structure in Canadian polar bears. Mol Ecol 4:347-354

Palsbøll PJ, Allen J, Bérubé M, Clapham PJ and others (1997) Genetic tagging of humpback whales. Nature 388: 767-769

Paterson RA, Paterson P, Cato DH (2001) Status of humpback whales, Megaptera novaeangliae, in east Australia at the end of the 20th century. Mem Queensl Mus 47: 579-586

Paterson R, Paterson P, Cato DH (2004) Continued increase in east Australian humpback whales in 2001, 2002. Mem Queensl Mus 49:712

Paton D, Brooks L, Burns D, Franklin T and others (2011) Abundance of east coast Australian humpback whales (Megaptera novaeangliae) in 2005 estimated using multi-point sampling and capture-recapture analysis. J Cetacean Res Manag Spec Issue 3:253-260

> Peakall R, Smouse PE (2006) GENALEX 6: genetic analysis in Excel. Population genetic software for teaching and research. Mol Ecol Notes 6:288-295

Pompanon F, Bonin A, Bellemain E, Taberlet P (2005) Genotyping errors: causes, consequences and solutions. Nat Rev Genet 6:847-859

Poole MM (2002) Occurrence of humpback whales (Megaptera novaeangliae) in French Polynesia in 1998-2001. Paper SC/54/HW14. International Whaling Commission, Cambridge

Poole MM (2006) An update on the occurrence of humpback whales in French Polynesia. Paper SC/A06/HW60. International Whaling Commission, Cambridge

> Pradel R (1996) Utilization of capture-mark-recapture for the study of recruitment and population growth rate. Biometrics 52:703-709

Rayner MJ, Clout MN, Stamp RK, Imber MJ, and others (2007) Predictive habitat modelling for the populations census of a burrowing seabird: a study of the endangered Cook's petrel. Biol Conserv 138:235-247

Robbins J, Mattila DK (2006) Summary of humpback whale research at American Samoa, 2003-2005. Paper SC/58/ SH5. International Whaling Commission, Cambridge

Robbins J, Dalla Rosa L, Allen JM, Mattila DK and others
(2011) Return movement of a humpback whale between the Antarctic Peninsula and American Samoa: a seasonal migration record. Endang Species Res 13:117-121

Rousset F (2008) GENEPOP'007: a complete re-implementation of the GENEPOP software for Windows and Linux. Mol Ecol Resour 8:103-106

Sambrook J, Fritsch EF, Maniatis T (1989) Molecular cloning: a laboratory manual. Cold Spring Harbor Laboratory, Cold Spring Harbor, NY

Schaffar A, Garrigue C, Constantine R (2010) Exposure of humpback whales to the unregulated whale-watching activities in their main reproductive area in New Caledonia. J Cetacean Res Manag 11:147-152

Schlotteröer C, Amos B, Tautz D (1991) Conservation of polymorphic simple sequence loci in cetacean species. Nature 354:63-65

Schwarz C, Arnason AN (1996) A general methodology for the analysis of open-model capture recapture experiments. Biometrics 52:860-873

Smith TD, Allen J, Clapham PJ, Hammond PS and others (1999) An ocean-basin-wide mark-recapture study of the North Atlantic humpback whale (Megaptera novaeangliae). Mar Mamm Sci 15:1-32

Stanley TR, Burnham KP (1999) A closure test for timespecific capture-recapture data. Environ Ecol Stat 6: 197-209

Steel D, Garrigue C, Hauser N, Olavarria C and others (2008) Migratory connections between humpback whales from South Pacific breeding grounds and Antarctic feeding areas based on genotype matching. Paper SC/60/SH13. International Whaling Commission, Cambridge

> Stephens PA, Sutherland WA (1999) Consequences of the Allee effect for behaviour, ecology and conservation. Trends Ecol Evol 14:401-405

- Stevick PT, Allen J, Clapham PJ, Friday N and others (2003) North Atlantic humpback whale abundance and rate of increase four decades after protection from whaling. Mar Ecol Prog Ser 258:263-273

Stevick PT, Incze LS, Kraus SD, Rosen S and others (2008) Trophic relationships and oceanography on and around a small offshore bank. Mar Ecol Prog Ser 363:15-28

Taylor BL, Chivers SJ, Larese J, Perrin WF (2007) Generation length and percent mature estimates for IUCN assessments of cetaceans. Administrative report LJ-0701. National Marine Fisheries Service, Southwest Fisheries Science Center, La Jolla, CA

Valsecchi E, Amos W (1996) Microsatellite markers for the study of cetacean populations. Mol Ecol 5:151-156

> Valsecchi E, Corkeron PJ, Galli P, Sherwin W, Bertorelle G (2010) Genetic evidence for sex-specific migratory behaviour in western South Pacific humpback whales. Mar Ecol Prog Ser 398:275-286

Waits JL, Leberg PL (2000) Biases associated with population estimation using molecular tagging. Anim Conserv 3:191-199

Waits LP, Luikart G, Taberlet P (2001) Estimating the probability of identity among genotypes in natural populations: cautions and guidelines. Mol Ecol 10:249-256

> Waldick RC, Brown MW, White BN (1999) Characterization and isolation of microsatellite loci from the endangered North Atlantic right whale. Mol Ecol 8:1763-1765

White GC, Burnham KP (1999) Program MARK: survival estimation from populations of marked animals. Bird Study 46(Suppl):S120-S138 